\title{
The Impact of Poplar Short Rotation Coppice on Topsoil Physical Properties and Related Water Conditions
}

\author{
Victoria Virano Riquelme ${ }^{1}$ - Gabriela Fontenla-Razzetto ${ }^{1} \cdot$ Filipa Tavares Wahren $^{1} \cdot$ Karl-Heinz Feger $^{1} \cdot$ Bálint Heil $^{2}$. \\ Dávid Heilig $^{2} \cdot$ Gábor Kovacs $^{2} \cdot$ Stefan Julich $^{1}$
}

Received: 8 July 2020 / Accepted: 5 March 2021 / Published online: 16 March 2021

(C) The Author(s) 2021

\begin{abstract}
In Europe, the establishment of short rotation coppice (SRC) systems for biomass production has been expanding in the last decades. Several studies have considered the impacts of SRC on soil properties; many have focused on studying its effect on biochemical properties while only a few have addressed physical and hydraulic properties. This study reports the assessment of soil physical and hydraulic properties on two SRC sites on sandy soils planted with 3-year-old poplar trees and an adjacent conventional agricultural field in Western Slovakia. All sites contain a comparable sandy loam soil texture and both SRC fields differed only in the groundwater accessibility. Water infiltration experiments were conducted in the field with subsequent sampling of the upper topsoil ( $0-5 \mathrm{~cm}$ depth). The samples were further processed in the laboratory to obtain the water retention and hydraulic conductivity functions of the soil covering a wide range of soil pore saturation. These hydraulic functions were fitted by using the bimodal version of Kosugi-Mualem's hydraulic model to estimate the pore-size distribution (PSD) of the soils. The comparison between the SRC field neighboring the agricultural field and the latter showed similar hydraulic soil properties such as the topsoil water retention. However, macropore content, bulk density (BD) and infiltration capacity differed under SRC particularly in the tree row. Analogously, the two SRC fields showed similar topsoil water contents. Other soil properties differed presenting an increased macropore content and higher BD in the SRC field with distant groundwater connection. Our findings suggest that the SRC management may influence the topsoil properties.
\end{abstract}

Keywords Short rotation coppice (SRC) · topsoil properties · pore-size distribution · Kosugi-Mualem model

\section{Introduction}

Poplar plantations for bioenergy or dendromass production have been expanding in Europe in the last decades. This development has been largely supported by policy makers under the framework of the EU Biomass Action Plan and the Renewable Energy Directive [1] since products derived from agriculture and forestry play a key role to mitigate climate change and to secure energy supply.

Increasing biomass production led to growing implementation of SRC systems which particularly on former agricultural fields show promising yield developments [2]. The rapid

Victoria Virano Riquelme

Victoria.virano@tu-dresden.de

1 Institute of Soil Science and Site Ecology, Faculty of Environmental Sciences, Technische Universität Dresden, Tharandt, Germany

2 Institute of Environmental and Earth Sciences, University of Sopron, Sopron, Hungary establishment of plantations implies a substantial change in the management practices which may have consequences on soil and water resources.

The impacts of SRC on water resources have been widely studied [3-7]. Soil-related investigations have mainly focused on the impacts of SRC on soil ecology [8-13], whereas changes on soil physical properties have been poorly studied. Evaluations of soil properties mainly occurred as part of an assessment of site characteristics affecting SRC size, quality and sustainability of yields [14, 15].

For a sustainable management of SRC plantations, the water availability in the soil needs to be considered. Soil hydraulic properties such as water storage depend on soil structure, and on soil hydraulic properties, both are affected by land use and land management which dynamically change over the course of the season $[13,14,16,17]$. The impact of SRC on soil hydraulic properties can be determined by relating the water retention and hydraulic conductivity functions through hydraulic functions [17] using a combination of field and laboratory experiments. For example, the application of the 
bimodal version of Kosugi-Mualem's model has shown that it is possible to assess the impact of land management change on the pore-size distribution of the soil [17-19].

These methods have been found reliable to study the effects of machinery work on soil properties in agricultural fields. Kreiselmeier et al. [20] state that the goodness of fit between field and laboratory measurements improves with the application of the bimodal version of Kosugi's model predicting an appropriate representation of the hydraulic functions.

Despite its importance, only few studies have concentrated on the effects of SRC on the soil PSD and focussed on macroporosity [20], which is mainly attributed to root growth. Likewise, research related to changes of soil physical properties such as BD or infiltration capacity in the period after the establishment of SRC has been poorly done. Makeschin [15] found an increased BD due to natural compaction after site preparation. Kahle and Janssen [20] reported reduced BD in the top $10 \mathrm{~cm}$ by comparing a SRC plantation and an adjacent agricultural land. To date, the understanding related to the effects of management operations in SRC on soil hydraulic properties within the plantation sites itself is insufficient.

In the presented study, we determined the impact of SRC management on soil physical properties. We did infiltration experiments with subsequent sampling of the upper topsoil. Two sites with 3-year-old SRC poplar hybrid clones differing only in their accessibility to groundwater were selected. As a control, one adjacent agricultural site with comparable soil properties was chosen. Regarding soil texture, all sites were similar and dominated by sand.

The objectives of this study were to (1) evaluate the impact of SRC on the topsoil hydraulic properties (water storage infiltration capacity and PSD) in contrast to an adjacent agricultural field and (2) to analyse the effect on SRC topsoil properties brought by different groundwater accessibility. We hypothesize that there are differences in soil hydraulic properties and PSD between the agricultural site and the SRC. Furthermore, we expect to see differences in the topsoil properties between SRC systems with different groundwater connection.

\section{Materials and Methods}

\section{Study Site and Sampling Design}

The present study took place in the Skalica area in western Slovakia characterized by a European continental warm and temperate climate. The mean annual precipitation is $518 \mathrm{~mm}$ with minimum and maximum precipitation occurring in February and June respectively (1982-2012, data obtained from climate-data.org). The coldest month in the year is January and the warmest month is July. The temperature ranges from -5 to $25{ }^{\circ} \mathrm{C}$ and the topography is predominantly plane with no slopes.

Our assessment involved field experiments and sampling to measure soil hydraulic properties. The experiments were performed on three adjacent sites (Fig. 1): two under poplar SRC sites, with statistically different groundwater accessibility $(p<0.05)$, SRC-D (D stands for distant groundwater access) and SRC-N (N stands for near groundwater access) and one agricultural land. The overall soil texture in all fields is classified as a sandy loam [21].

SRC sites and the agricultural field differ in their land management. On the one hand, the agricultural field is subjected to more intense practices within a year, such as machinery work for seeding, harvesting and specific weed and pest control. On the other hand, SRC fields after the tree planting weed control have been done once a year and no fertilizers have been applied. SRC fields are historical agricultural sites which have been converted to marginal lands until the establishment of SRC. In the agricultural field, the crop rotation comprised winter wheat, sunflower and corn. At time of sampling, the agricultural field was planted with winter wheat.

At the beginning of our study, the poplars in both SRC fields were growing in their third year which represents the early stage of the SRC after its establishment. The tree diameter at breast height (DBH) was measured in a total of 21 and 20 trees in field SRC-N and SRC-D, respectively, presenting the former one a smaller range of values. Tree height was measured and average values were visibly smaller in field SRC-D. Data for DBH of both sites is given in Table 1.

\section{Sampling and Analysis for Soil Hydraulic Properties}

Sampling was conducted in the end of March 2019. Since variations in soil structure are expected to be larger in the topsoil [22], we collected undisturbed soil cores $\left(250 \mathrm{~cm}^{3}\right)$ from a depth of 0 to $5 \mathrm{~cm}$. Undisturbed samples were taken, four in the agricultural site and nine in each SRC sites, by thoroughly removing the litter layer and small herbaceous vegetation.

In each SRC, the samples were taken in different sub-areas: the tree row, the wheel lane and the middle lane (Fig. 1). In the tree lane, the samples were taken exactly in the middle between trees (separated by $1.5 \mathrm{~m}$ ) and between consecutive trees. The samples from the wheel lane were around $1 \mathrm{~m}$ distant from the tree lane and the middle lane. In the agricultural field, samples were taken sequentially in line. Distance between the sampling points was $1 \mathrm{~m}$ for a total line length of $5 \mathrm{~m}$ distant from the site edges to avoid additional compaction.

Additional to the soil cores, disturbed samples were taken. They were air-dried and divided into sub-samples for the analysis of texture and total $\mathrm{C}$ and N. For the $\mathrm{CN}$ analysis, subsamples were ground and measured with the Vario TOCтM cube (Elementar, Hanau, Germany). As there was no 

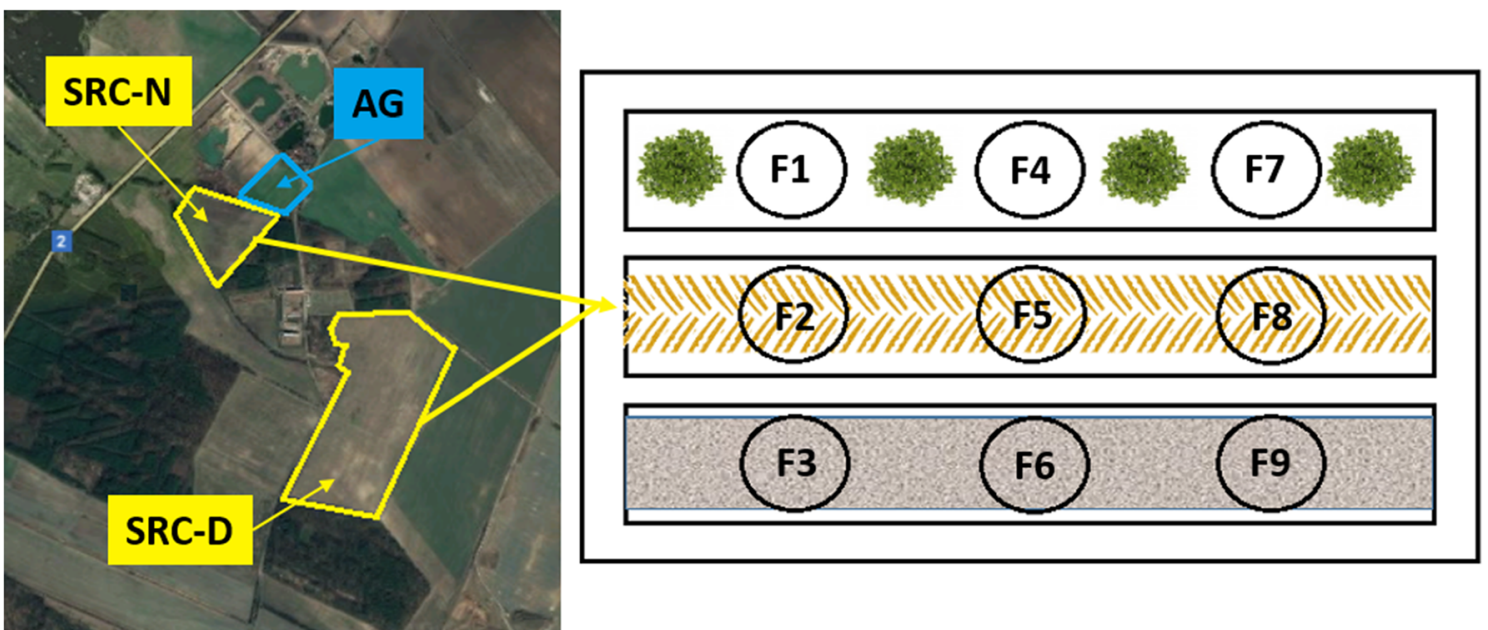

Fig. 1 SRC sites and agricultural field boundaries and locations. The sampling design in each SRC field considers three sub-areas with three repetitions. The considered sub-areas are the poplar tree row—PL (F1, F4, F7); the wheel lane-WL (F2, F5, F8); and the middle lane-ML (F3, F6, F9)

carbonate present in the soil, total $\mathrm{C}$ content can be assumed to represent organic C. Independent sub-samples were used to determine the soil texture by combined sieving and sedimentation analysis. Before analysis, organic matter was removed with the addition of hydrogen peroxide and particles have been dispersed by the addition of sodium diphosphate.

Prior to the collection of the undisturbed samples, infiltration in the topsoil was measured with a hood infiltrometer [23]. The data from the infiltration experiments were evaluated according to Kreiselmeier et al. [17].

For the determination of the water retention and hydraulic conductivity characteristics, the HYPROP® device (METER Group Inc.) was used. This device works under the Schindler's simplified evaporation method [24], based on the Wind's approach [25] which yielded reliable results [26]. The HYPROP® system comprises a sensor with two tensio shafts which were carefully inserted in the soil samples. These sensors are positioned at different depths $(1.25$ and $3.75 \mathrm{~cm})$ [27]. They are able to record the pressure within the soil at 10 15-min intervals until the air entry point of one of the tensio shafts is reached (after 6-7 days) [26, 27]. The whole system was positioned in a scale to record the weight variations in the sample due to water evaporation.

At the end of the evaporation experiment, the samples were carefully sieved (2-mm sieve), where it was evident that the overall samples from field SRC-D showed a high content of roots in comparison to SRC-N and the agricultural field. From the sieved material sub-samples, $30-40 \mathrm{~mL}$ was taken to proceed with the determination of the permanent wilting point (PWP) which was determined in the laboratory by means of the ceramic pressure plates. The sub-samples were placed in small rings and positioned directly in contact with the

Table 1 Summary of field characteristics. Field A: agricultural field. Fields SRC-D and SRC-N: SRC sites

\begin{tabular}{|c|c|c|c|}
\hline Subject & Field A & Field SRC-N & Field SRC-D \\
\hline Field coordinates & $48^{\circ} 46^{\prime} 9.08^{\prime \prime} \mathrm{N} 17^{\circ} 5^{\prime} 49.41^{\prime \prime} \mathrm{E}$ & $48^{\circ} 46^{\prime} 9.08^{\prime \prime} \mathrm{N} 17^{\circ} 5^{\prime} 49.41^{\prime \prime} \mathrm{E}$ & $48^{\circ} 45^{\prime} 51.90^{\prime \prime} \mathrm{N} 17^{\circ} 6^{\prime} 28.80^{\prime \prime} \mathrm{E}$ \\
\hline Current crop & Winter wheat & Hybrid poplar & Hybrid poplar \\
\hline Sand [Mass-\%] & 75.9 & 72.3 & 83.7 \\
\hline Silt [Mass-\%] & 15.1 & 16.6 & 11.9 \\
\hline Clay [Mass-\%] & 9.0 & 11.1 & 4.4 \\
\hline Main texture group $(*)$ & Loamy sand & Loamy sand & Loamy sand \\
\hline Total C [mass\%] & 1.09 & 2.01 & 0.41 \\
\hline Total N [mass\%] & 0.11 & 0.20 & 0.04 \\
\hline Mean groundwater below surface $[\mathrm{m}]$ & 1.8 & 1.8 & 3.1 \\
\hline Poplar mean DBH $[\mathrm{cm}](* *)$ & - & 9.5 & 5.5 \\
\hline Poplar mean height [m] (***) & - & 6.8 & 3.3 \\
\hline
\end{tabular}

*Soil texture classes according to German Classification (Bodenkundliche Kartieranleitung, 2005). **DBH, diameter at breast height. ***Ökoforestino survey $2017-2018$ 
previously fully saturated ceramic plate inside the pressure chamber. The container was pressurized at 15 bar until no more water was extracted from inside (5-6 days). The remaining soil from the sieving was oven-dried $\left(105^{\circ} \mathrm{C}, 24 \mathrm{~h}\right)$ to calculate the remaining water content $(\theta \mathrm{r})$ and $\mathrm{BD}$ (particle density assumed as $2.65 \mathrm{~g} \mathrm{~cm}^{-3}$ ).

To process the results obtained from the abovementioned devices, the software HYPROP-Fit [28] was employed. The predictive model selected in the software on the basis of an appropriate representation of the curves was the bimodal version of the Kosugi's [29] and Mualem's [19] model which is based on the assumption of a lognormal distribution of the soil PSD [30]. The Kosugi bimodal model was selected in accordance with Kreiselmeier et al. [22], since it is able to represent the structural and textural domains of the pore-size distribution. The parameters of this model have a physical meaning; therefore, it is adequate to assess the soil physical properties through its PSD [31].

The water retention and the hydraulic conductivity functions by Kosugi-Mualem's model are given by Eqs. 1 and 2, respectively. The bimodality of the curve is identified by $k=2$ and both sub-curves are determined by $i=1$ and $i=2$, structural and textural domains respectively.

$S_{e}(h)=\frac{\theta-\theta_{r}}{\theta_{s}-\theta_{r}}=\sum_{i=1}^{k} w_{i}\left\{\frac{1}{2} \operatorname{erfc}\left[\frac{\ln \frac{h}{h_{m i}}}{\sqrt{2} \sigma_{i}}\right]\right\}$

$\mathrm{S}_{\mathrm{e}}(-)$ represents the effective saturation as a function of the pressure head $\mathrm{h}(\mathrm{cm})$. Parameters $\theta, \theta_{\mathrm{s}}$ and $\theta_{\mathrm{r}}\left(\mathrm{cm}^{3} \mathrm{~cm}^{-3}\right)$ are the volumetric saturated and residual water content respectively, $\mathrm{w}_{\mathrm{i}}(-)$ is a weighing factor for each sub-curve $\left(0 \leq \mathrm{w}_{\mathrm{i}} \leq 1 ; \Sigma\right.$ $\left.\mathrm{w}_{\mathrm{i}}=1\right)$, erfc is the complementary error function, $\mathrm{h}_{\mathrm{mi}}(\mathrm{cm})$ is the median pressure head at which the effective saturation of the respective sub-curve $\mathrm{S}_{\mathrm{ei}}\left(\mathrm{h}_{\mathrm{mi}}\right)=0.5$, and $\sigma_{\mathrm{i}}(-)$ is the standard deviation of the lognormal soil pore radius defining the width of the PSD.

$K(h)=K_{\text {sat }} \frac{S_{e}^{0.5}}{4\left[\sum_{i=1}^{k} \frac{w_{i}}{h_{m i}} \exp \frac{\sigma_{i}^{2}}{2}\right]^{2}}\left\{\sum_{i=1}^{k} \frac{w_{i}}{h_{m i}} \exp \frac{\sigma_{i}^{2}}{2} \operatorname{erfc}\left[\frac{\sigma_{i}}{\sqrt{2}} \operatorname{erfc}^{-1} 2 S_{e i}\right]\right\}^{2}$

From the hydraulic function parameterization, KosugiMualem's model provides relevant parameters to assess the PSD of the soil since it represents the relative abundance of each pore size in a representative volume of soil [29, 32]. Such parameters are $\mathrm{h}_{\mathrm{m} 1,2} ; \sigma_{1,2} ; \mathrm{w}_{1,2} ; \theta_{\mathrm{r}} ; \theta_{\mathrm{s}} ;$ and $\mathrm{r}_{\mathrm{m} 1,2}$, where the last one corresponds to the median pore radius derived from $\mathrm{h}_{\mathrm{mi}}$ through the Young-Laplace equation $\left(\mathrm{r}_{\mathrm{mi}}=0.149 \mathrm{~cm}^{2} / \mathrm{h}_{\mathrm{mi}}\right.$ [31]). The PSD of the soil can be estimated by applying Eq. 3 [15]. It calculates the volume fraction taken up by different pore size classification, involving the parameter $\Phi$ which represents the porosity defined as $\theta_{\mathrm{s}}-\theta_{\mathrm{r}}$. $g(r)=\sum_{i=1}^{k} w_{i} \frac{\Phi}{\sqrt{2 \pi} \sigma_{i} r} \exp \left[-\frac{\ln \frac{r_{m i}^{2}}{r_{m i}^{2}}}{2 \sigma_{i}^{2}}\right]$

We used the pore-size category classification by Brewer [33]. It covers a wide range of radius divided in three major classes (with $r=$ pore radius): micropores $(5>r>30 \mu \mathrm{m})$, mesopores $(30>r>75 \mu \mathrm{m})$ and macropores $(r>75 \mu \mathrm{m})$.

\section{Results}

\section{Soil Texture, C and N Contents and Soil Bulk Density}

Soil texture and total C and $\mathrm{N}$ contents found in the topsoil of all analysed fields are presented in Table 1 . The highest total $\mathrm{C}$ and $\mathrm{N}$ contents were found in SRC-N. In contrast, these parameters were reduced to half in the agricultural field. The dominating soil particle-size fraction found in all fields was sand. The highest content of sand was found in SRC-D, whereas field SRC-N presented the highest silt and clay contents.

The BD found in SRC-N (mean $1.27 \mathrm{~g} \mathrm{~cm}^{-3}$ ) was similar to the agricultural field (mean $1.30 \mathrm{~g} \mathrm{~cm}^{-3}$ ), both classified as low values [21] (Fig. 2). Field SRC-D showed BD variations when compared to SRC-N (Fig. 2). The average BD in field SRC-D $\left(1.47 \mathrm{~g} \mathrm{~cm}^{-3}\right)$ was $15 \%$ higher. The most prominent variation was seen in the wheel lane, presenting values ranging from 1.25 up to $1.49 \mathrm{~g} \mathrm{~cm}^{-3}$.

\section{Infiltration Capacity and Water Retention}

The mean infiltration capacity determined with the hood infiltrometer in the different areas within field SRC-N ranged from 1.68 to $2.62 \log 10 \mathrm{~cm} \mathrm{~d}^{-1}$ where the highest values were found in the tree line and the lowest in the middle lane (Fig. 3). In the case of SRC-D, the highest infiltration capacity was found in the poplar and the middle lane (2.41 and 2.45 $\log 10 \mathrm{~cm} \mathrm{~d}^{-1}$ correspondingly), whereas the lowest was in the wheeled area $\left(1.64 \log 10 \mathrm{~cm} \mathrm{~d}^{-1}\right)$. The overall infiltration capacity seen in the SRC fields exhibited comparable values in contrast to the mean value found in the agricultural field of $2.34 \log 10 \mathrm{~cm} \mathrm{~d}^{-1}$. Comparing the two SRC fields, only the tree rows presented similar infiltration capacity values (Fig. 3 ), showing a high spatial variability.

The different sub-areas in SRC-N showed comparable water contents at field capacity (FC) and plant available water (PAW) (Fig. 4). On average, the water contents at such stages were $24.1 \mathrm{vol} \%$ and $17.6 \mathrm{vol} \%$ accordingly, representing lower values when compared to the agricultural field.

The water content at FC in field SRC-D showed lower values, on average $16 \mathrm{vol} \%$ of the topsoil, in contrast to 
Fig. 2 Comparison of bulk density (BD) in the topsoil samples between the agricultural field (A) and both SRC fields (SRC-D and SRC-N). The BD values are presented according to the different analysed areas: (A) agricultural practices, (PL) poplar tree row, (WL) wheel lane and (ML) middle lane

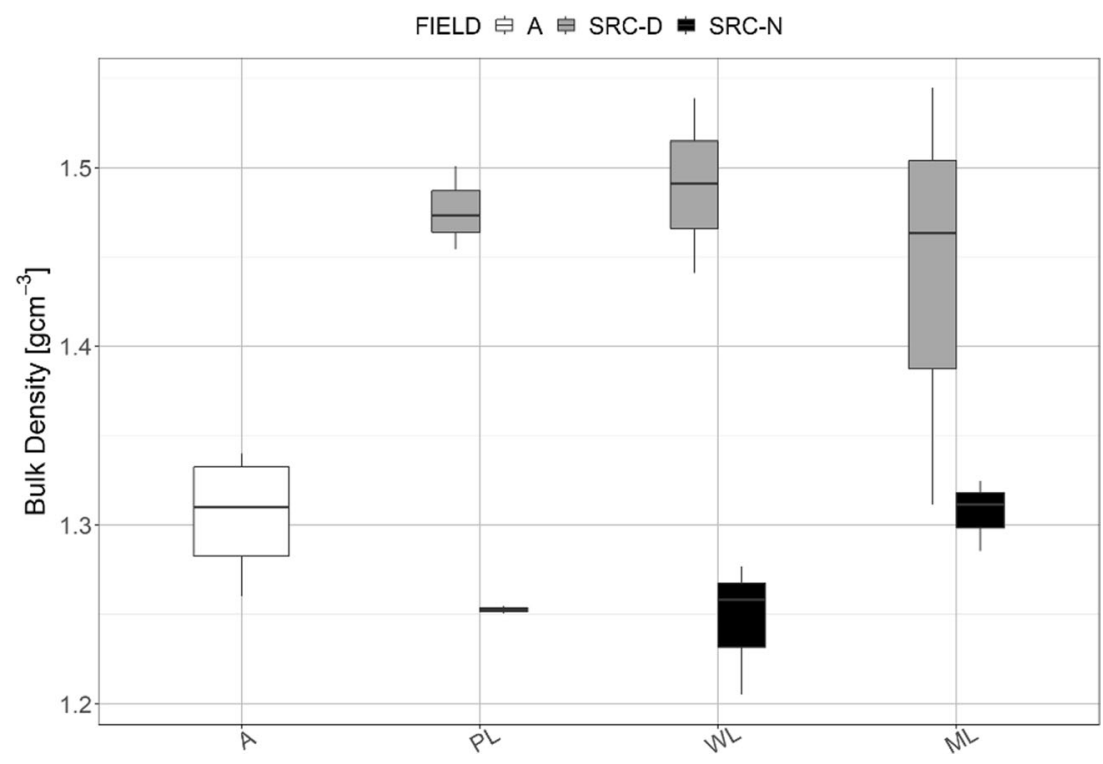

SRC-N (Fig. 4). However, the average water content at PAW showed only a $4.5 \%$ variation between both SRC fields.

\section{Porosity and Pore-Size Distribution}

Mean total porosity between SRC fields and the agricultural field was comparable, ranging from 44 to 59 vol\% (Fig. 4). However, some sub-areas in the SRC fields presented a slightly higher porosity than the agricultural field. Such results were seen in the tree row in both SRC fields and particularly in the middle line in SRC-D, which presented the highest porosity.

Figure 5 shows the PSD of the topsoil, calculated using the parameters from Kosugi-Mualem's fitting in Eq. 3. Results demonstrate that in the agricultural field, the micropore content $(59 \%)$ dominated over the macro-meso pore fraction $(41 \%)$. Field SRC-N showed an overall increased macropore content in comparison to the agricultural field. Such results point to an enhanced infiltration of water in the upper soil layer in this sub-area, evidenced by the infiltration capacity measurements. The pore variation within field SRC-N was largest in the tree row, presenting a $19 \%$ higher total macropore fraction and accordingly reduction of micropore content (Fig. 5). In contrast, the wheeled sub-area presented higher micropore fractions, which was comparable to the one found in the middle lane and the agricultural field. Similarly to our results, Kahle and Janssen [34] found that the first $20 \mathrm{~cm}$ soil layer in a SRC plantation had higher total porosity than under cropland. Unlike results from SRC-N and the agricultural field, SRC-D exhibited a larger volume of macropores (Fig. 5). Surprisingly, the average macro- and mesopore contents in this field were $16 \%$ and $42 \%$ higher, respectively, having consequently a $58 \%$ micropore reduction.
Fig. 3 Comparison of infiltration capacity in the topsoil samples between the agricultural field (A) and both SRC fields (SRC-D and SRC-N). Results are presented according to the different analysed areas: (A) agricultural practices, (PL) poplar tree row, (WL) wheeled lane and (ML) middle lane

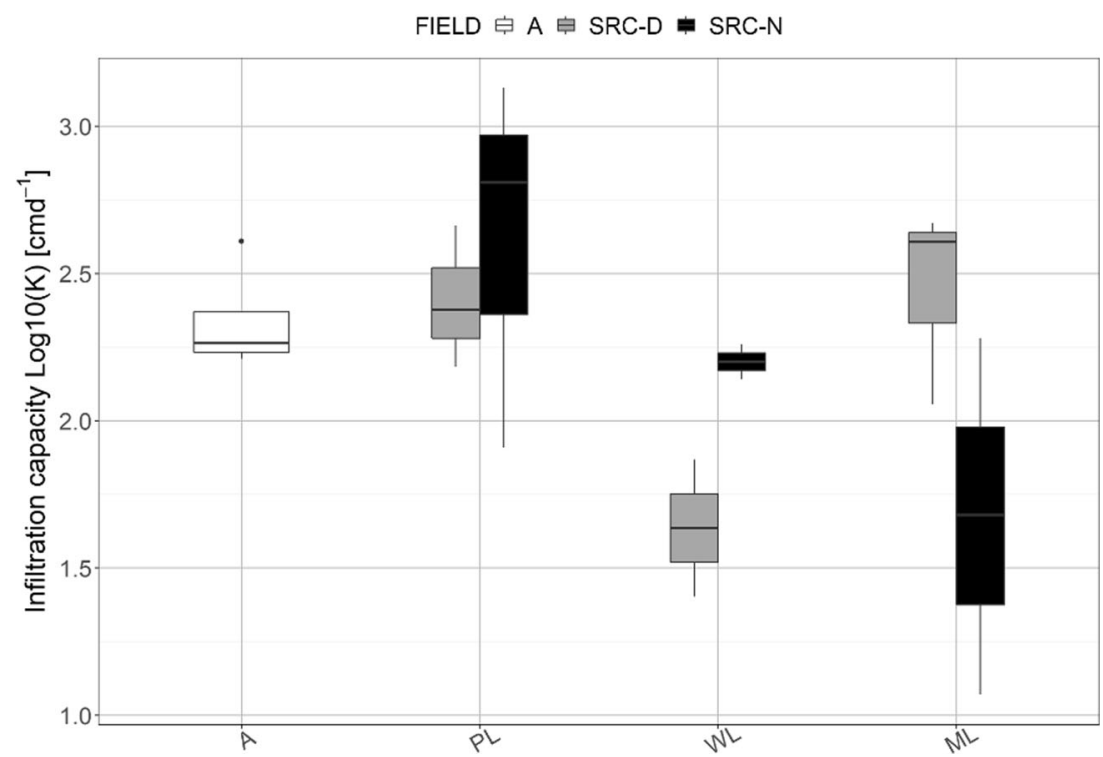


Fig. 4 Comparison of topsoil water content at field capacity (FC), the plant available water (PAW), and the total porosity between agricultural field (A) and both SRC fields (SRC-D and SRC-N). Values from each analysed sub-area within the SRC fields are depicted: (PL) poplar tree row, (WL) wheeled lane and (ML) middle lane

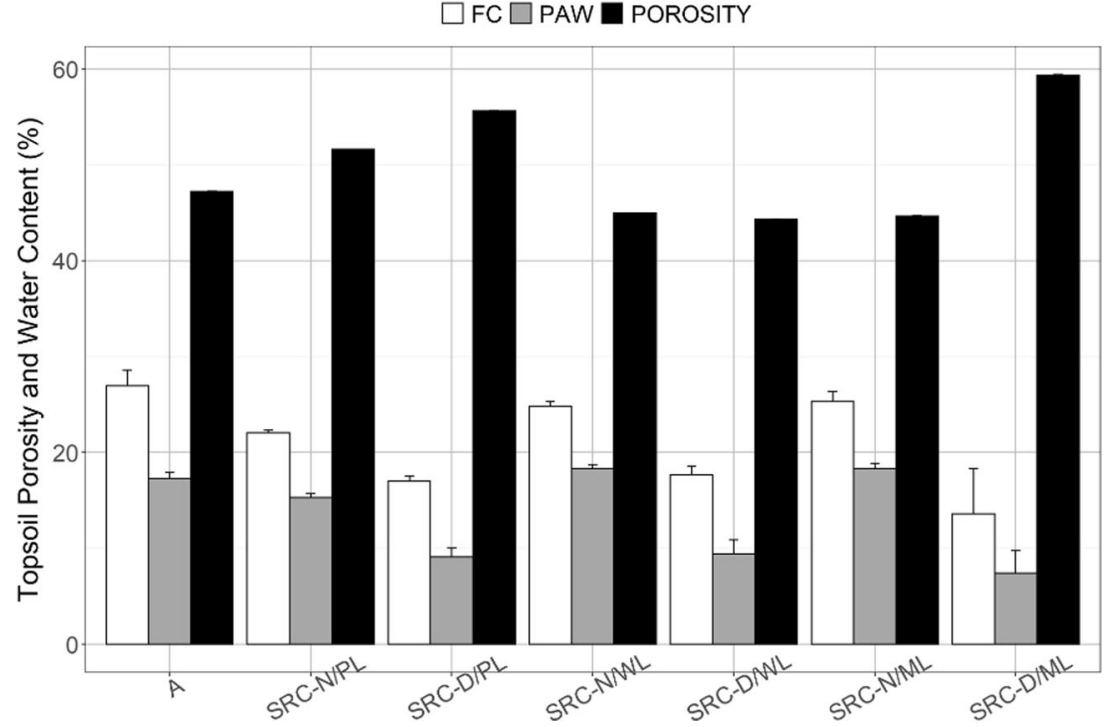

\section{Discussion}

\section{Influence of SRC on Total Soil CN and BD}

Previous studies reported that SRC plantations have a high input of $\mathrm{C}$ in the topsoil, developing biological and soil fauna activity [11]. For example, Dong et al. [35] found higher litter deposition under SRC in comparison to abandoned lands, increasing the $\mathrm{C}$ content in the topsoil even at early stages of the plantation (0.5-5 years). Similarly, Kahle et al. [36] found increased total $\mathrm{C}$ and $\mathrm{N}$ contents in a 12-year-old poplar $\mathrm{SRC}$ in contrast to a former agricultural land, which was

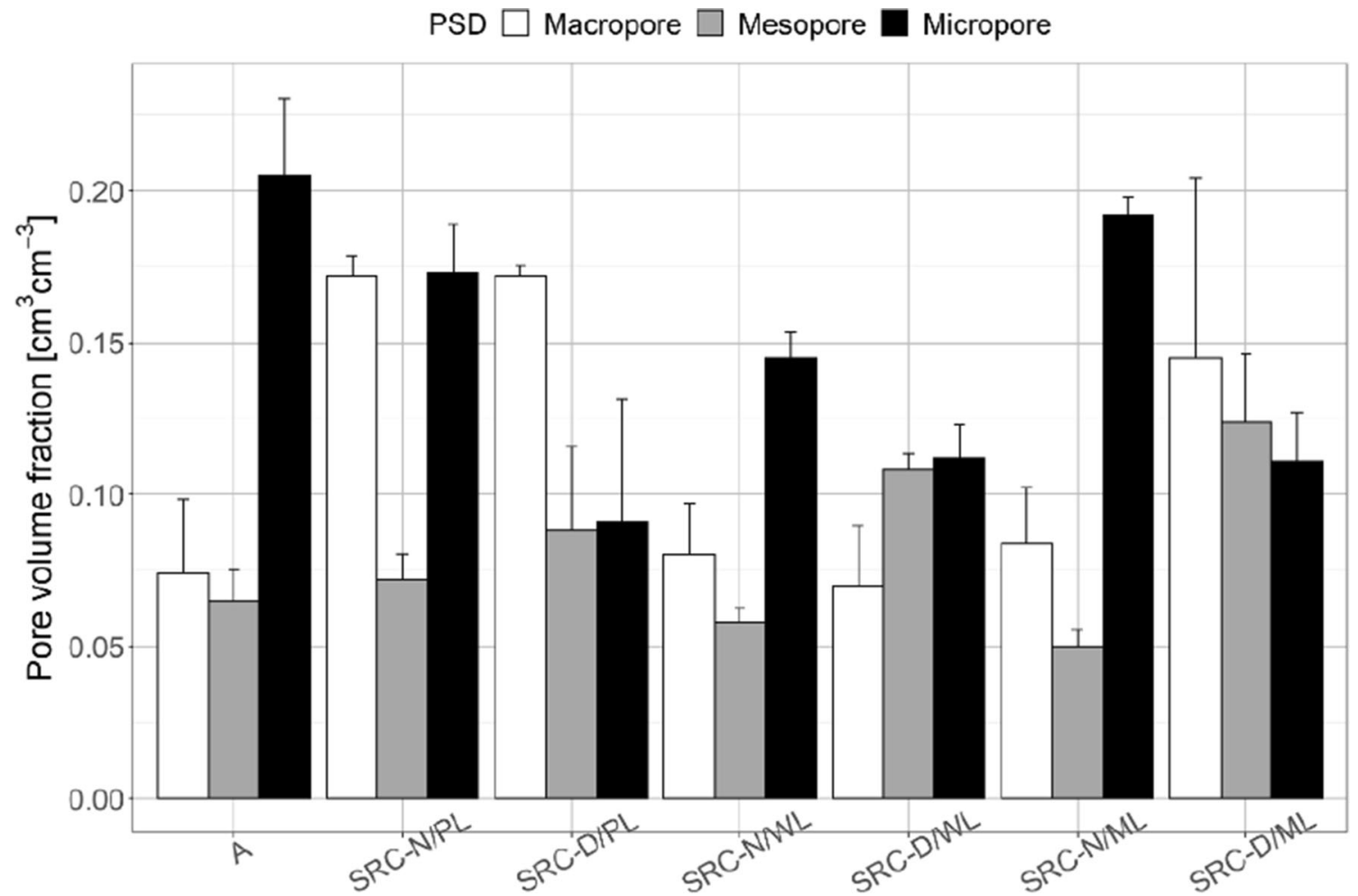

Fig. 5 Pore-size distribution (PSD) from Kosugi-Mualem's parameters considering porosity $(\Phi)$ defined as the difference between saturated $\left(\theta_{\mathrm{s}}\right)$ and the residual $\left(\theta_{\mathrm{r}}\right)$ water content (Eq. 3) and classified according to Brewer. The PSD is grouped according to the different analysed areas:
(A) agricultural practices, (PL) poplar tree row, (WL) wheeled lane and (ML) middle lane. Standard deviation from topsoil replicates in each field are shown (replicates: $\mathrm{AG}=4, \mathrm{SRC}-\mathrm{D}=3$ in each sub-area and SRC-N = 3 in each sub-area) 
further related to a high microbial activity. Our study took place in an early stage SRC field presenting higher total $\mathrm{C}$ and $\mathrm{N}$ contents compared to an adjacent agricultural site.

Total $\mathrm{C}$ and $\mathrm{N}$ contents clearly differed when comparing SRC-N to SRC-D and the agricultural field. We attributed these results to the site characteristics such as access to groundwater and the soil texture. The higher content of clay and silt in field SRC-N likely enhanced the nutrient retention, such as the $\mathrm{N}$ content. Probably the poor connection to groundwater in field SRC-D limited the total $\mathrm{C}$ and $\mathrm{N}$ contents in the upper topsoil and consequently the poplar trees yield. Likewise, Zhang et al. [37] reported a decrease in the total soil $\mathrm{C}$ and $\mathrm{N}$ contents with increasing groundwater distance to surface. The effect of groundwater accessibility was further seen when contrasting poplar tree characteristics on both SRC sites. SRC-N presented larger DBH and height values in contrast to SRC-D (Table 1).

Observed BD values in SRC-N and the agricultural field were found within the same magnitude; however, the tree and the wheeled area particularly were slightly lower. Different from our results, Kahle and Janssen [34] found significantly lower BD in the upper $10 \mathrm{~cm}$ of a sandy loam soil under an 18year-old SRC (1.35 and $1.38 \mathrm{~g} \mathrm{~cm}^{-3}$ ) compared to mediumhigh BD in an adjacent agricultural system (1.58 and $1.65 \mathrm{~g}$ $\mathrm{cm}^{-3}$ ), probably due to the advanced SRC stage.

Other studies have been conducted in further stages of SRC poplar and willow plantations (18 and 24 years old), where loosened soil was found with substantially lower BD in comparison to agricultural lands [36, 38]. For instance, Kahle et al. [36] also found decreased BD in a 12-year-old poplar SRC with sandy soil in contrast to a set-a-side agricultural land. Similarly, Dong et al. [35] found lower BD in a sandy soil under SRC in contrast to a briefly afforested site which was harvested and abandoned later on. They described that BD under SRC after 3.5 and 5 years were 1.38 and $1.36 \mathrm{~g} \mathrm{~cm}^{-3}$ accordingly, whereas in the abandoned land, the BD was $1.55 \mathrm{~g} \mathrm{~cm}^{-3}$. However, similarly to our findings, Kahle and Janssen [34] found comparable BD between an agricultural field (1.64/1.69 $\mathrm{g} \mathrm{cm}^{-3}$ ) and a SRC upon the establishment $\left(1.65 \mathrm{~g} \mathrm{~cm}^{-3}\right)$, though their results correspond to high BD values unlike our results.

Regarding the SRC sub-area assessment, it was expected to find highly compacted soil in the wheel lane within the SRC since the management practices and machinery wheeling induce soil compaction, reducing soil porosity with subsequently increment in BD [39, 40]. For example, Souch et al. [38] reported that in a SRC with sandy clay soil, the machinery compaction significantly increased the $\mathrm{BD}$ at $0.1 \mathrm{~m}$ depth in the furrowed area from 1.40 to $1.70 \mathrm{~g} \mathrm{~cm}^{-3}$. Surprisingly, in our study, the wheeled area in the SRC-N showed comparable BD to the tree row (Fig. 2).

Our results suggest that the low BD might be a consequence of the potentially increased soil fauna activity under
SRC due to higher total $\mathrm{C}$ and $\mathrm{N}$ contents, likely loosening the soil and increasing the macropore content. Similar BD values found in the wheeled sub-area in contrast to the agricultural field suggest that the machinery compaction under SRC might not affect the topsoil properties as crop rotation practices. The $\mathrm{BD}$ found in the agricultural field was comparable to that described by Kreiselmeier et al. [22] indicating that the influence of soil management (ploughing and seedbed preparation) can still be noticed at the beginning of the growing season for winter wheat.

Overall, BD between SRC fields was higher in field SRC$\mathrm{D}$ even though the same management was applied in both. We attribute such differences in BD values to the poor groundwater access in SRC-D coupled to distinct clay and silt content. As mentioned before, fields exposed to deep groundwater levels may present low $\mathrm{C}$ and $\mathrm{N}$ contents due to the potential reduced soil fauna activity together with increased $\mathrm{BD}$ on the topsoil $(0-30 \mathrm{~cm})$ [37]. Within field SRC-D, the highest BD was found in the wheel lane.

\section{Influence of SRC on Infiltration Capacity and Soil Water Content}

Field SRC-N presented a higher infiltration capacity in the tree row in contrast to the agricultural field. This may be due to the low BD together with the highest content of macropores in the topsoil. Similar to our results, German and Beven [41] described that soils with high macropore contents are characterized by increased infiltration capacity. Likewise, GonzalezSosa et al. [40] showed higher infiltration capacity in soils beneath tree hedges in contrast to agricultural lands.

Field SRC-D appeared to have similar infiltration capacity in the tree row when compared to SRC-N, indicating that the higher macropore fraction in SRC-D compensated the higher BD. The wheel lane in field SRC-D presented the lowest infiltration capacity within the field and a lower infiltration capacity in contrast to the same lane in field SRC-N, probably related to the high $\mathrm{BD}$, enhancing the machinery effect. The largest infiltration capacity was found in field SRC-N in the middle lane attributed to the lower amount of micropore content (only $29 \%$ in comparison to $59 \%$ in SRC-N).

Comparing the agricultural field with field SRC-N, water retention capacity values were similar. However, the agricultural field presented slightly higher values. This finding may be related to the higher micropore fraction in this field in contrast to the higher macropore content found in field SRC-N.

Similarly to our results, Kahle and Janssen [34] showed no considerable differences of water content at FC contrasting a SRC with a cropland at $0-10 \mathrm{~cm}$ depth. However, they reported that the PAW was higher in the upper soil layer under SRC. Our results differed from their study probably due to the different tree stage. They found higher PAW in an 18-year-old 
SRC system, whereas our study took place in the first years of the SRC after the establishment.

The visibly lower water content in field SRC-D at FC and PAW in comparison to SRC-N was attributed to two conditions: different soil texture and site characteristics, namely access to groundwater. Field SRC-D presented around 13\% more sand content with accordingly decreased silt-clay particles than SRC-N and enhanced macro-mesopore fraction. These characteristics in combination likely diminished the water retention capacity of the soil in field SRC-D which probably after gravity drainage is not able to hold as much water as the topsoil from field SRC-N.

\section{Influence of SRC on PSD}

The SRC field presented an overall higher macropore content with a respective decrease of micropores in contrast to the agricultural field, especially in the tree row. These results may be related to the potential biological activity under SRC due to higher $\mathrm{C}$ and $\mathrm{N}$ contents, likely enhancing the aggregate stability and widening the pores in the soil $[39,40]$. Similarly, Kahle et al. [36] related the increased total pore volume in a 12-year-old poplar SRC to a higher microbial activity.

Despite the identical management practices between both SRC fields, different soil pore distributions were found on the SRC fields. The higher content of macropores in field SRC-D was attributed to the abundant weed roots found in the upper topsoil samples. Root growth as well as decaying roots has been reported as an influencing factor to increase the macropore content in the soil [42].

In the field SRC-N, a distinct enhancement of macropore content was observed. This has an impact in other site characteristics such as the infiltration capacity, $\mathrm{BD}$, or groundwater recharge. Changes were more pronounced in the tree row. A better water infiltration may then further supply deeper soil zones and thus enhance the effective soil water availability of the profile, where the rooting system of the trees can access the water.

\section{Conclusions}

Within the SRC plantation, increased macropore fraction with a subsequent decrease of micropores was observed, particularly in the tree row. Enhanced soil BD accounting for a larger water infiltration was seen. Likewise, the topsoil conditions in the wheel lane were rather favourable despite the exposure to machinery compaction. Therefore, we conclude that under favourable conditions, SRC plantations, even in early stages, may have a beneficial impact on the upper topsoil properties in contrast to conventional cropland, likely overcoming the effect of machinery compaction. Such effects were not seen in the field with poor groundwater connection.
Soil properties showed appreciable differences contrasting SRC fields regardless of the identical management practices. They appeared to be susceptible not only to management practices but probably also to the contrasting site characteristics concerning the potential influence of the groundwater table. Thus, our study underlines that great attention must be given to the site selection to establish an SRC, especially to groundwater availability.

Furthermore, this study raises more questions for further investigation related to the SRC impact on soil properties, for instance including a more robust sampling design to cover analysis in deeper horizons to supplement our findings. Likewise, it would be interesting to expand studies related to topsoil properties using the Kosugi's bimodal hydraulic model to assess the impact of SRC with different tree ages (different SRC stages), diverse soil textures and varying access to groundwater.

Moreover, accurate information of soil properties is fundamental for the modeling of water fluxes of SRC systems. Thus, our study provides knowledge regarding the spatially differentiated variability of soil physical and hydraulic properties, which may account for a better quantification of soil water fluxes in hydrological models.

Despite some limitations in the results, our study and the developed methodology provide a framework for future studies to assess the impact of SRC on soil hydraulic properties for a better and sustainable resource management.

Funding Open Access funding enabled and organized by Projekt DEAL. This study has been supported by the Bio-based Industries Joint Undertaking under the European Union's Horizon 2020 research and innovation program under grant agreement No $745874 »$ Dendromass for Europe« (D4EU).

Data Availability The raw data is proprietary but can be disclosed by sending a motivated request to the corresponding author.

\section{Declarations}

Conflict of Interest The authors declare no conflicts of interest.

Ethics Approval and Consent to Participate This study did not include human or animal testing. All individuals involved with the experiment were informed about the study purpose and methods and agreed to participate.

Consent for Publication All partners agreed with publication in the present form.

Open Access This article is licensed under a Creative Commons Attribution 4.0 International License, which permits use, sharing, adaptation, distribution and reproduction in any medium or format, as long as you give appropriate credit to the original author(s) and the source, provide a link to the Creative Commons licence, and indicate if changes were made. The images or other third party material in this article are included in the article's Creative Commons licence, unless indicated otherwise in a credit line to the material. If material is not included in the article's 
Creative Commons licence and your intended use is not permitted by statutory regulation or exceeds the permitted use, you will need to obtain permission directly from the copyright holder. To view a copy of this licence, visit http://creativecommons.org/licenses/by/4.0/.

\section{References}

1. Schope M (2008) Renewable energy directive. European Wind Energy Conference and Exhibition 1:32-38

2. Spinelli R, Nati C, Magagnotti N (2009) Using modified foragers to harvest short-rotation poplar plantations. Biomass Bioenergy 33(5): 817-821. https://doi.org/10.1016/j.biombioe.2009.01.001

3. Petzold R, Schwärzel K, Feger K-H (2011) Transpiration of a hybrid poplar plantation in Saxony (Germany) in response to climate and soil conditions. Eur J For Res 130(5):695-706. https://doi.org/ 10.1007/s10342-010-0459-Z

4. Schmidt-Walter P, Lamersdorf NP (2012) Biomass production with willow and poplar short rotation coppices on sensitive areas - the impact on nitrate leaching and groundwater recharge in a drinking water catchment near Hanover, Germany. Bioenergy Res 5(3):546562. https://doi.org/10.1007/s12155-012-9237-8

5. Hartwich J, Schmidt M, Bölscher J, Reinhardt-Imjela C, Murach D, Schulte A (2016) Hydrological modelling of changes in the water balance due to the impact of woody biomass production in the North German Plain. Environ Earth Sci 75(14). https://doi.org/10. 1007/s12665-016-5870-4

6. Dimitriou L, Busch G, Jacobs S, Schmidt-Walter P, Lamersdorf N (2009) A review of the impacts of short rotation coppice cultivation on water issues. Landbauforschung - vTI Agric For Res 59(3):197_ 206

7. Wahren A, Richter F, Julich S, Jansen M, Feger K-H (2015) The influence of more widespread cultivation of short rotation coppice on the water balance: from the site to the regional scale. In: Bioenergy from dendromass for the sustainable development of rural areas. Wiley-VCH Verlag GmbH \& Co. KGaA, Weinheim, pp 45-62. https://doi.org/10.1002/9783527682973.ch5

8. Dimitriou I, Mola-Yudego B (2017) Impact of populus plantations on water and soil quality. Bioenergy Res 10(3):750-759. https:// doi.org/10.1007/s12155-017-9836-5

9. Kern J, Germer S, Ammon C, Balasus A, Bischoff W, Schwarz A, Forstreuter M, Kaupenjohann M (2018) Environmental effects over the first 21/2 rotation periods of a fertilised poplar short rotation coppice. Bioenergy Res 11(3):152-165. https://doi.org/10.1007/ s12155-017-9885-9

10. Jug A, Makeschin F, Rehfuess K, Hofmann-Schielle C (1999) Short-rotation plantations of balsam poplars, aspen and willows on former arable land in the Federal Republic of Germany. III. Soil ecological effects. For Ecol Manag 121(1-2):85-99. https:// doi.org/10.1016/S0378-1127(98)00558-1

11. Baum C, Leinweber P, Weih M, Lamersdorf N, Dimitriou L (2009) Effects of short rotation coppice with willows and poplar on soil ecology. Landbauforschung - vTI Agric For Res 59(3):183-196

12. Tsonkova P, Böhm C, Quinkenstein A, Freese D (2012) Ecological benefits provided by alley cropping systems for production of woody biomass in the temperate region: a review. Agrofor Syst 85(1):133-152. https://doi.org/10.1007/s10457-012-9494-8

13. Stauffer M, Leyval C, Brun JJ, Leportier P, Berthelin J (2014) Effect of willow short rotation coppice on soil properties after three years of growth as compared to forest, grassland and arable land uses. Plant Soil 377(1-2):423-438. https://doi.org/10.1007/ s11104-013-1986-4
14. Bergante S, Facciotto G, Minotta G (2010) Identification of the main site factors and management intensity affecting the establishment of short-rotation-coppices (SRC) in Northern Italy through stepwise regression analysis. Open Life Sci 5(4):522-530. https:// doi.org/10.2478/s11535-010-0028-y

15. Makeschin F (1999) Short rotation forestry in central and northern Europe - introduction and conclusions. For Ecol Manag 121(1-2): $1-7$

16. Weninger T, Bodner G, Kreiselmeier J, Chandrasekhar P, Julich S, Feger K-H, Schwärzel K, Schwen A (2018) Combination of measurement methods for a wide-range description of hydraulic soil properties. Water 10(8):1-15. https://doi.org/10.3390/w10081021

17. Kreiselmeier J, Chandrasekhar P, Weninger T, Schwen A, Julich S, Feger K-H, Schwärzel K (2020) Temporal variations of the hydraulic conductivity characteristic under conventional and conservation tillage. Geoderma 362:114127. https://doi.org/10.1016/j.geoderma. 2019.114127

18. Kosugi K (1997) A new model to analyze water retention characteristics of forest soils based on soil pore radius distribution. J For Res 2(1):1-8. https://doi.org/10.1007/BF02348255

19. Mualem Y (1976) A new model for predicting the hydraulic conductivity of unsaturated porous media. Water Resour Res 12(3): 513-522. https://doi.org/10.1029/WR012i003p00513

20. Kahle P, Janssen M (2020) Impact of short-rotation coppice with poplar and willow on soil physical properties. J Plant Nutr Soil Sci 183(26):119-128. https://doi.org/10.1002/jpln.201900443

21. Boden AG (2005) Bodenkundliche Kartieranleitung, 5th edn. Bundesanstalt für Geowissenschaften und Rohstoffe, Hannover, $p$ 438

22. Kreiselmeier J, Chandrasekhar P, Weninger T, Schwen A, Julich S, Feger K-H, Schwärzel K (2019) Quantification of soil pore dynamics during a winter wheat cropping cycle under different tillage regimes. Soil Tillage Res 192:222-232. https://doi.org/10.1016/j. still.2019.05.014

23. Schwärzel K, Punzel J (2007) Hood infiltrometer - a new type of tension infiltrometer. Soil Sci Soc Am J 71(5):1438. https://doi.org/ 10.2136/sssaj2006.0104

24. Schindler U, Müller L (2006) Simplifying the evaporation method for quantifying soil hydraulic properties. J Plant Nutr Soil Sci 169(5):623-629. https://doi.org/10.1002/jpln.200521895

25. Wind GP (1969) Capillary conductivity data estimated by a simple method. In: Water in the unsaturated zone proceedings of the Wageningen Symposium. IASH/AIHS - Unesco 1:181-191

26. Peters A, Durner W (2008) Simplified evaporation method for determining soil hydraulic properties. J Hydrol 356(1-2):147-162. https://doi.org/10.1016/j.jhydrol.2008.04.016

27. UMS (2015) Manual HYPROP. UMS GmbH, Munich, p 96

28. Pertassek T, Peters A, Durner W, Durner W (2011) HYPROP data evaluation software. UMS GmbH, München, pp 1-47

29. Kosugi K (1996) Lognormal distribution model for unsaturated soil hydraulic properties. Water Resour Res 32:2697-2703. https://doi. org/10.1029/96WR01776

30. Romano N, Nasta $\mathrm{P}$ (2016) How effective is bimodal soil hydraulic characterization? Functional evaluations for predictions of soil water balance. Eur J Soil Sci 67(4):523-535. https://doi.org/10.1111/ ejss. 12354

31. Seki K (2010) SWRC fit-a nonlinear fitting program with a water retention curve for soils having unimodal and bimodal pore structure. Hydrol Earth Syst Sci Discuss 4(1):407-437. https://doi.org/ 10.5194/hessd-4-407-2007

32. Nimmo JR (2005) Porosity and pore-size distribution. In: Hillel D (ed) Encycl. Soils Environ. Elsevier, London, pp 295-303. https:// doi.org/10.1016/b0-12-348530-4/00404-5

33. Brewer R (1965) Fabric and mineral analysis of soils. In: Soil Sci. Soc. of America J. Wiley, New York, p 470 
34. Kahle P, Janssen M (2020) Impact of short-rotation coppice with poplar and willow on soil physical properties. J Plant Nutr Soil Sci 183(2):1-10. https://doi.org/10.1002/jpln.201900443

35. Dong TL, Doyle R, Beadle CL, Corkrey R, Quat NX (2014) Impact of short-rotation Acacia hybrid plantations on soil properties of degraded lands in Central Vietnam. Soil Res 52(3):271-280. https://doi.org/10.1071/SR13166

36. Kahle P, Hildebrand E, Baum C, Boelcke B (2007) Long-term effects of short rotation forestry with willows and poplar on soil properties. Arch Agron Soil Sci 53(6):673-682. https://doi.org/10. 1080/03650340701648484

37. Zhang X, Guan T, Zhou J, Cai W, Gao N, Du H, Jiang L, Lai L, Zheng Y (2018) Groundwater depth and soil properties are associated with variation in vegetation of a desert riparian ecosystem in an arid area of China. Forests 9(1):1-18. https://doi.org/10.3390/ f9010034

38. Souch CA, Martin PJ, Stephens W, Spoor G (2004) Effects of soil compaction and mechanical damage at harvest on growth and biomass production of short rotation coppice willow. Plant Soil 263(12):173-182. https://doi.org/10.1023/B:PLSO.0000047734.91437. 26
39. Shah AN, Tanveer M, Shahzad B, Yang G, Fahad S, Ali S, Bukhari MA, Tung SA, Hafeez A, Souliyanonh B (2017) Soil compaction effects on soil health and cropproductivity: an overview. Environ Sci Pollut Res 24(11):10056-10067. https://doi.org/10.1007/ s11356-017-8421-y

40. Gonzalez-Sosa E, Braud I, Dehotin J, Lassabatère L, AnguloJaramillo R, Lagouy M, Branger F, Jacqueminet C, Kermadi S, Michel K (2010) Impact of land use on the hydraulic properties of the topsoil in a small French catchment. Hydrol Process 24(17):2382-2399. https://doi.org/10.1002/hyp.7640

41. Germann P, Beven K (1982) Macropores and water flow in soils. Water Resour Res 18(5):1311-1325. https://doi.org/10.1029/ WR018i005p01311

42. Stirzaker RJ, Passioura JB, Wilms Y (1996) Soil structure and plant growth: impact of bulk density and biopores. Plant Soil 185(1): 151-162. https://doi.org/10.1007/BF02257571

Publisher's Note Springer Nature remains neutral with regard to jurisdictional claims in published maps and institutional affiliations. 